\title{
REVISED National culture as a correlate of research performance
}

\section{and impact [version 2; peer review: 2 approved with}

\section{reservations]}

Previously titled: National culture as a correlate of research impact and productivity

Juneman Abraham

Psychology Department, Faculty of Humanities, Bina Nusantara University, Jakarta, 11480, Indonesia

V2 First published: 28 Feb 2019, 8:237

https://doi.org/10.12688/f1000research.18283.1

Second version: 24 Sep 2019, 8:237

https://doi.org/10.12688/f1000research.18283.2

Latest published: 07 Feb 2020, 8:237

https://doi.org/10.12688/f1000research.18283.3

\section{Abstract}

National culture has been overlooked in discussions related to research performance and impact owing to individual, socio-political structure, and economic factors. This study shows the relationships between the dimensions of cultural value orientation of the nation and research performance \& impact. More than 60 countries were included and Spearman correlation analysis was employed. The variables were taken from Geert Hofstede and Scimago Journal \& Country Rank worksheets. This study found that (1) Power distance the positive inclination of the culture toward power disparities among people - is negatively correlated with research impact; (2)

Individualism - the level of independence a society keeps up among its individuals - are positively correlated with research performance and research impact; (3) Indulgence - the degree to which society members do not attempt to control their urges - is positively correlated with research impact; and (4) after controlling the Log GDP per capita, uncertainty avoidance - the manner in which that a society seeks to manage the actuality that the future can never be controlled is negatively correlated with research impact.

\section{Keywords}

research impact, research productivity, national culture, individualism, indulgence, power distance, citations per document, self citations

\section{Open Peer Review}

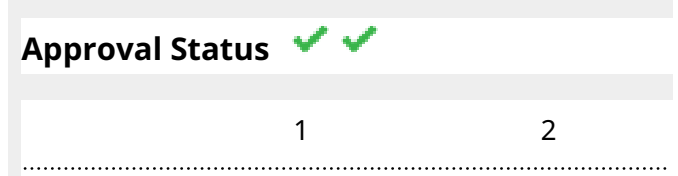

\section{version 3}

(revision)

07 Feb 2020

version 2

(revision)

24 Sep 2019

version 1

28 Feb 2019
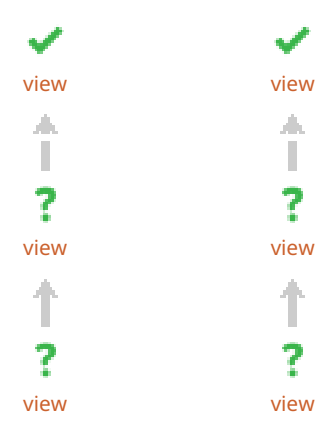

1. Jonathan P. Tennant ID, IGDORE, Berlin, Germany

\section{Ludo Waltman iD, Leiden University,}

Leiden, The Netherlands

Any reports and responses or comments on the article can be found at the end of the article.

This article is included in the Research on

Research, Policy \& Culture gateway. 
Corresponding author: Juneman Abraham (juneman@binus.ac.id)

Author roles: Abraham J: Conceptualization, Data Curation, Formal Analysis, Investigation, Methodology, Resources, Writing - Original Draft Preparation, Writing - Review \& Editing

Competing interests: No competing interests were disclosed.

Grant information: The author(s) declared that no grants were involved in supporting this work.

Copyright: () 2019 Abraham J. This is an open access article distributed under the terms of the Creative Commons Attribution License, which permits unrestricted use, distribution, and reproduction in any medium, provided the original work is properly cited.

How to cite this article: Abraham J. National culture as a correlate of research performance and impact [version 2; peer review: 2 approved with reservations] F1000Research 2019, 8:237 https://doi.org/10.12688/f1000research.18283.2

First published: 28 Feb 2019, 8:237 https://doi.org/10.12688/f1000research.18283.1 


\section{REVISED Amendments from Version 1}

I changed the title of the article based on two components formed, i.e. research performance and impact, as the results of the principal component analysis on the Scimago Journal \& Country Rank bibliometric variables. I added a table containing the results of the non-parametric test of differences on research performance and impact between the world's regions. The table on descriptive statistics was constructed more comprehensively. A figure was added depicting PCA component plots. Two figures were added in the form of scatter plots that show the coordinate points connecting the national culture dimensions with research performance and impact of the highest and lowest groups. Discussions related to tables and figures were presented in more depth.

Any further responses from the reviewers can be found at the end of the article

\section{Introduction}

Makri (2018) recently released a report on the increasing number of publications in various countries. She stated that it's unclear what has triggered and driven the strong gains in Egypt and Pakistan. Throughout the report, various variables believed to be responsible for the increasing number of publications, such as indexation duration, funding, global engagement, international collaboration, and political policies on science and higher education, are explained.

Several predictors of research performance and impact had been identified, i.e. author characteristics, co-authorship networks, citation history, journal impact factors, tweets (Xiaomei et al., 2017), cohort effects (in terms of scientific discipline), age, career stages, gender, the country of origin of the $\mathrm{PhD}$ holders, and reward structure of the research enactment (Claudia \& Francisco, 2007). They are mostly at the individual and institutional level. At the country level, the predictors are the number of universities, GDP per capita, control of corruption, civil liberties (Mueller et al., 2016), country's wealth and population size, country's value of research tradition, tenure and promotion criterion, experimental costs, IRB (Institutional Review Boards) review flexibility, language barrier, and the training of new young researchers (Demaria, 2009).

However, national cultural orientation (in this paper, the term is used interchangeably with: national culture, national cultural value, national culture dimension) is yet to be analyzed, with the present study assuming that individual, institutional, and structural factors are also influenced by the cultural values of a nation. Hofstede Insights (2019) defined culture as the collective mental programming of the human mind which distinguishes one group of people from another, consisting of six dimensions, i.e. (1) power distance (PDI) - acceptance on the unequal power distribution in a society; (2) uncertainty avoidance (UAI) - intolerance of ambiguity and uncustomary thoughts and practices; (3) individualism (IDV) - projection of individuals' "I" in a society rather than "we" (collectivism); (4) masculinity (MAS) - the toughness and competitiveness rather than the tenderness and cooperativeness (femininity) orientation; (5) long term orientation (LTOWVS) - the society's preference of time-honored rather than pragmatic approaches (short term normative orientation); and (6) indulgence (IVR) - the society facilitation towards a fun and enjoyable life rather than restraint (suppression of needs gratification by strict social norms).

National culture is relatively stable (Maseland \& van Hoorn, 2017) and is widely used to explain various performances at the country level, such as learning and academic performance (Signorini et al., 2009). The present study hypothesized that there are correlations between the national culture dimensions and research performance indicators. The research performance is assumed to be mediated by research culture, and the culture experiences stimulations and challenges from the national culture.

\section{Methods}

All following data were retrieved on August 18, 2019, and compiled into a worksheet (see Underlying data (Abraham, 2019) as the material of this present analysis. Countries' region, total documents/DOC, citable documents/CITA, citations/CIT, self-citations/SELF, H-index/HINDEX, and citations per document/CPD (1996-18 August 2019) were obtained from the Scimago Journal \& Country Rank/SCIMAGOJR (https://www. scimagojr.com/countryrank.php?out=xls), while national cultural orientations $(P D I=$ power distance, $I D V=$ individualism, $M A S=$ masculinity, $U A I=$ uncertainty avoidance, $L T O W V S=$ long term orientation, $I V R=$ indulgence) were acquired from Geert Hofstede web site (https://geerthofstede.com/wp-content/ uploads/2016/08/6-dimensions-for-website-2015-08-16.xls). Countries' GDP per Capita (1993-2018) were taken from the World Bank Open Data (http://api.worldbank.org/v2/en/indicator/ NY.GDP.PCAP.PP.CD?downloadformat=excel), being calculated as natural logarithm $(l n)$ of the average measures.

Principal component analysis (PCA) and Independentsamples Kruskal-Wallis $\mathrm{H}$ Test were done using IBM SPSS Statistics version 25 for Windows to get two major components from dimensions reduction of DOC, CITA, CIT, SELF, HINDEX, and CPD, as well as comparison between countries' regions in terms of the reduced dimensions. Correlation analysis was conducted using JASP version 0.10.2 for Windows, and Partial correlation analysis was conducted using IBM SPSS Statistics.

\section{Results}

The data analysis results are presented in Table 1.

\section{Discussion}

The purpose of this study is to show whether there are correlations between national cultural values and research performance and impact. Because correlation is not causation, the following analysis and interpretation do not attempt to state definitively that there is a causal effect from one variable to another. Even though in this discussion cultural value orientation is often used as an explanation of research performance and impact, this is more due to the chronological flow that culture comes and envelops, engulfs a country first than the SCIMAGOJR measures. The argument is in line with the proposition of Sen (2004) that culture is a constituent of development and economic behavior, as expressed as follows: 
Table 1. Summary of the study's results.

\begin{tabular}{|c|c|c|}
\hline Type & Display & Results \\
\hline $\begin{array}{l}\text { Descriptive statistics } \\
\text { of SCIMAGOJR measures }\end{array}$ & Table 2 & The DOC, CITA, CIT, SELF, CPD, HINDEX data are not normally distributed. \\
\hline $\begin{array}{l}\text { Principal component analysis } \\
\text { of SCIMAGOJR measures }\end{array}$ & Table 3 \& Figure 1 & $\begin{array}{l}\text { There are } 2 \text { components extracted with a total variance explained 92.073\%, namely: } \\
\text { - Component 1: "Research Performance" (a synthesis of DOC, CITA, CIT, SELF, } \\
\text { HINDEX) } \\
\text { - Component 2: "Research Impact" (based on CPD alone) } \\
\text { The correlation between Components is weak (<0.2). It might be that CPD is more } \\
\text { difficult to manipulate or be an object of the author's engineering. }\end{array}$ \\
\hline $\begin{array}{l}\text { Comparison between regions } \\
\text { (Kruskal-Wallis H Test result) }\end{array}$ & Table 4 & $\begin{array}{l}\text { Mean comparisons result in terms of Research Performance: } \\
\text { - Eastern Europe > Latin America } \\
\text { - Eastern Europe > Pacific Region } \\
\text { - } \text { Eastern Europe > Africa } \\
\text { - Middle East > Latin America } \\
\text { - Middle East > Pacific Region } \\
\text { - Asiatic Region > Pacific Region } \\
\text { Mean comparisons result in terms of Research Impact: } \\
\text { - Latin America > Middle East } \\
\text { - Latin America > Asiatic Region } \\
\text { - Latin America > Eastern Europe }\end{array}$ \\
\hline $\begin{array}{l}\text { Descriptive statistics of } \\
\text { national culture, research } \\
\text { performance, and research } \\
\text { impact }\end{array}$ & Table 5 & $\begin{array}{l}\text { The data is not normally distributed; therefore, correlation analysis was done with } \\
\text { Spearman's correlation. }\end{array}$ \\
\hline $\begin{array}{l}\text { Plots of national cultures, } \\
\text { research performance, and } \\
\text { Log GDP per capita }\end{array}$ & $\begin{array}{l}\text { Figure } 2 \\
\text { (missing scores } \\
\text { do not bring up } \\
\text { the line) }\end{array}$ & $\begin{array}{l}\text { Based on low vs. high research performance criteria ( }<-0.30 \sigma \text { vs. }>0.30 \sigma \text { ), it is } \\
\text { found that, among } 33 \text { countries ( } 7 \text { low vs. } 26 \text { high), (1) United States, ( } 2) \text { China, } \\
\text { (3) United Kingdom, (4) Germany, and (5) Japan are countries with the highest } \\
\text { research performance. Descriptively, in each of these countries, the national cultural } \\
\text { orientations that play roles the most and the least are, respectively: } \\
\text { (1) Individualism, long term orientation; } \\
\text { (2) Long term orientation, individualism; } \\
\text { (3) Individualism, uncertainty avoidance; } \\
\text { (4) Long term orientation, power distance; } \\
\text { (5) Masculinity, indulgence. } \\
\text { For countries with the lowest research performance, there is no data available on } \\
\text { their national cultural orientation. }\end{array}$ \\
\hline $\begin{array}{l}\text { Plots of national cultures, } \\
\text { research impact, and Log } \\
\text { GDP per capita }\end{array}$ & $\begin{array}{l}\text { Figure } 3 \\
\text { (missing scores } \\
\text { do not bring up } \\
\text { the line) }\end{array}$ & $\begin{array}{l}\text { Based on low vs. high research impact criteria (<-1.50 } \sigma \text { vs. }>1.50 \sigma \text { ), it is found } \\
\text { that, among } 25 \text { countries ( } 4 \text { low vs. } 21 \text { high), (1) Anguilla, (2) Bermuda, (3) Gambia, } \\
\text { (4) Federated States of Micronesia, and (5) Belize are the countries with the highest } \\
\text { research impact. } \\
\text { Unfortunately, data are not yet available about the orientation of their cultural values. } \\
\text { The complete data (six cultural orientations) available are from (1) Belgium, and (2) } \\
\text { United Kingdom. Descriptively, in each of these countries, the cultural orientations } \\
\text { that play roles the most and the least are, respectively: } \\
\text { (1) Uncertainty avoidance, power distance; } \\
\text { (2) Individualism, uncertainty avoidance (as well as power distance). } \\
\text { For countries with the lowest research impact, there is no data available on national } \\
\text { cultural orientation. }\end{array}$ \\
\hline Spearman's correlation & Table 6 & $\begin{array}{l}\text { The results, with } q(\text { adjusted } p)<0.00714 \text {, are: } \\
\text { - } \quad \text { PDI is negatively correlated with Research Impact } \\
\text { - } \quad \text { IDV is positively correlated with Research Performance and Research Impact } \\
\text { - } \quad \text { IVR is positively correlated with Research Impact } \\
\text { - LGDP is positively correlated with Research Performance }\end{array}$ \\
\hline $\begin{array}{l}\text { Partial correlation (controlling } \\
\text { LGDP) }\end{array}$ & Table 7 & $\begin{array}{l}\text { The directions of correlation between variables are the same as the results of } \\
\text { Spearman's correlation above, but there is an additional new result: } \\
\text { - UAl is negatively correlated with Research Impact }\end{array}$ \\
\hline
\end{tabular}

DOC = Total documents (1996-18 August 2019); CITA = Total citable documents; CIT = Total citations; SELF = Total self-citations; CPD = Citations per document; HINDEX = H-index; PDI = Power distance; IDV = Individualism (vs. Collectivism); IVR = Indulgence (vs. Restraint); LGDP = Natural logarithm of averaged (1993-2018) GDP per capita. The operational definition of DOC, CITA, CIT, SELF, CPD, and HINDEX could be found at https://www.scimagojr.com/ help.php 
"The furtherance of well-being and freedoms that we seek in development cannot but include the enrichment of human lives through ... forms of cultural expression and practice, which we have reason to value .... Cultural influence can make a major difference to work ethics, responsible conduct, spirited motivation, dynamic management, entrepreneurial initiatives, willingness to take risks, and a variety of other aspects of human behavior which can be critical to economic success." (pp. 39-40).

In other words, culture can influence public policy which regulates human capital; whereas, research performance and impact depends on human capital, in addition to the fact that research is a contributor to economic growth and development (Blanco et al., 2015). However, this study is cautious for not trapping itself in cultural determinism.

\section{The limitation of SCIMAGOJR data}

There are a number of things that need to be stated from the beginning of this discussion, namely: Firstly, the SCIMAGOJR data (Table 2) includes both journal articles, conference proceedings papers, and does not exclude other types of documents (i.e. short survey, review) (Guerrero-Bote \& Moya-Anegón, 2012). A number of countries or institutions exclude nonjournal articles from evaluating their performance (e.g. Suryani et al., 2013), so the applicability of the results of this study to these countries might be limited. In this present study, data from SCIMAGOJR is used because, among others, it can be downloaded for free.

Secondly, in a number of dimensions of research performance and impact measurement (Table 3, Figure 1), Scopus, which supplies the data of SCIMAGOJR, has a number of limitations; for example (1) Scopus has poor coverage of articles, conference papers, and book chapters compared to Crossref, Dimensions, Google Scholar, and Microsoft Academic; (2) Scopus is somewhat late in indexing in-press articles compared to all four; (3) Socially, Scopus does not support open citation (Harzing, 2019). The first two limitations may affect the accuracy of research performance and impact measurements. The third limitation of Scopus is offset by its advantages, namely Scopus is still an extensive source of quality citation data (van Eck et al., 2018).

Table 2. Descriptive statistics of SCIMAGOJR indicators (1996-18 August 2019).

\begin{tabular}{|l|r|r|r|r|r|r|}
\hline & DOC & \multicolumn{1}{|c|}{ CITA } & \multicolumn{1}{c|}{ CIT } & SELF & CPD & HINDEX \\
\hline Valid & 239 & 239 & 239 & 239 & 239 & 239 \\
\hline Missing & 0 & 0 & 0 & 0 & 0 & 0 \\
\hline Mean & 226870.448 & 208895.238 & $4.041 \mathrm{e}+6$ & $1.209 \mathrm{e}+6$ & 14.289 & 191.904 \\
\hline Std. Error of Mean & 62573.389 & 56718.779 & $1.372 \mathrm{e}+6$ & 584905.378 & 0.451 & 17.893 \\
\hline Std. Deviation & 967361.125 & 876851.047 & $2.122 \mathrm{e}+7$ & $9.042 \mathrm{e}+6$ & 6.967 & 276.624 \\
\hline Variance & $9.358 \mathrm{e}+11$ & $7.689 \mathrm{e}+11$ & $4.501 \mathrm{e}+14$ & $8.177 \mathrm{e}+13$ & 48.541 & 76521.054 \\
\hline Shapiro-Wilk & 0.231 & 0.237 & 0.172 & 0.106 & 0.905 & 0.637 \\
\hline p of Shapiro-Wilk & $<.001$ & $<.001$ & $<.001$ & $<.001$ & $<.001$ & $<.001$ \\
\hline Minimum & 2.000 & 1.000 & 9.000 & 0.000 & 2.000 & 1.000 \\
\hline Maximum & $1.207 \mathrm{e}+7$ & $1.070 \mathrm{e}+7$ & $2.977 \mathrm{e}+8$ & $1.344 \mathrm{e}+8$ & 52.300 & 2222.000 \\
\hline
\end{tabular}

$\mathrm{DOC}=$ Total documents; CITA $=$ Total citable documents; $\mathrm{CIT}=$ Total citations; $\mathrm{SELF}=$ Total self-citations;

$\mathrm{CPD}=$ Citations per document; HINDEX $=\mathrm{H}$-index

Table 3. Component loadings of principal component analysis.

\begin{tabular}{|c|c|c|c|c|c|}
\hline & Component 1 & Component 2 & $\begin{array}{c}\text { Correlation between } \\
\text { Components }\end{array}$ & $\begin{array}{c}\text { KMO of Sampling } \\
\text { Adequacy }\end{array}$ & $\begin{array}{c}\text { Bartlett's Test of } \\
\text { Sphericity }\end{array}$ \\
\hline $\mathrm{CIT}$ & 0.981 & -0.043 & 0.159 & 0.662 & $\begin{array}{r}\chi^{2}(15)=3759.508 \\
p=0.000\end{array}$ \\
\hline CITA & 0.982 & -0.087 & & & \\
\hline CPD & 0.197 & 0.974 & & & \\
\hline DOC & 0.987 & -0.083 & & & \\
\hline HINDEX & 0.833 & 0.140 & & & \\
\hline SELF & 0.947 & -0.104 & & & \\
\hline Variance Explained & $75.498 \%$ & $16.575 \%$ & & & \\
\hline $\begin{array}{l}\text { Name of component } \\
\text { given by the author }\end{array}$ & $\begin{array}{l}\text { Research } \\
\text { Performance }\end{array}$ & $\begin{array}{l}\text { Research } \\
\text { Impact }\end{array}$ & & & \\
\hline
\end{tabular}




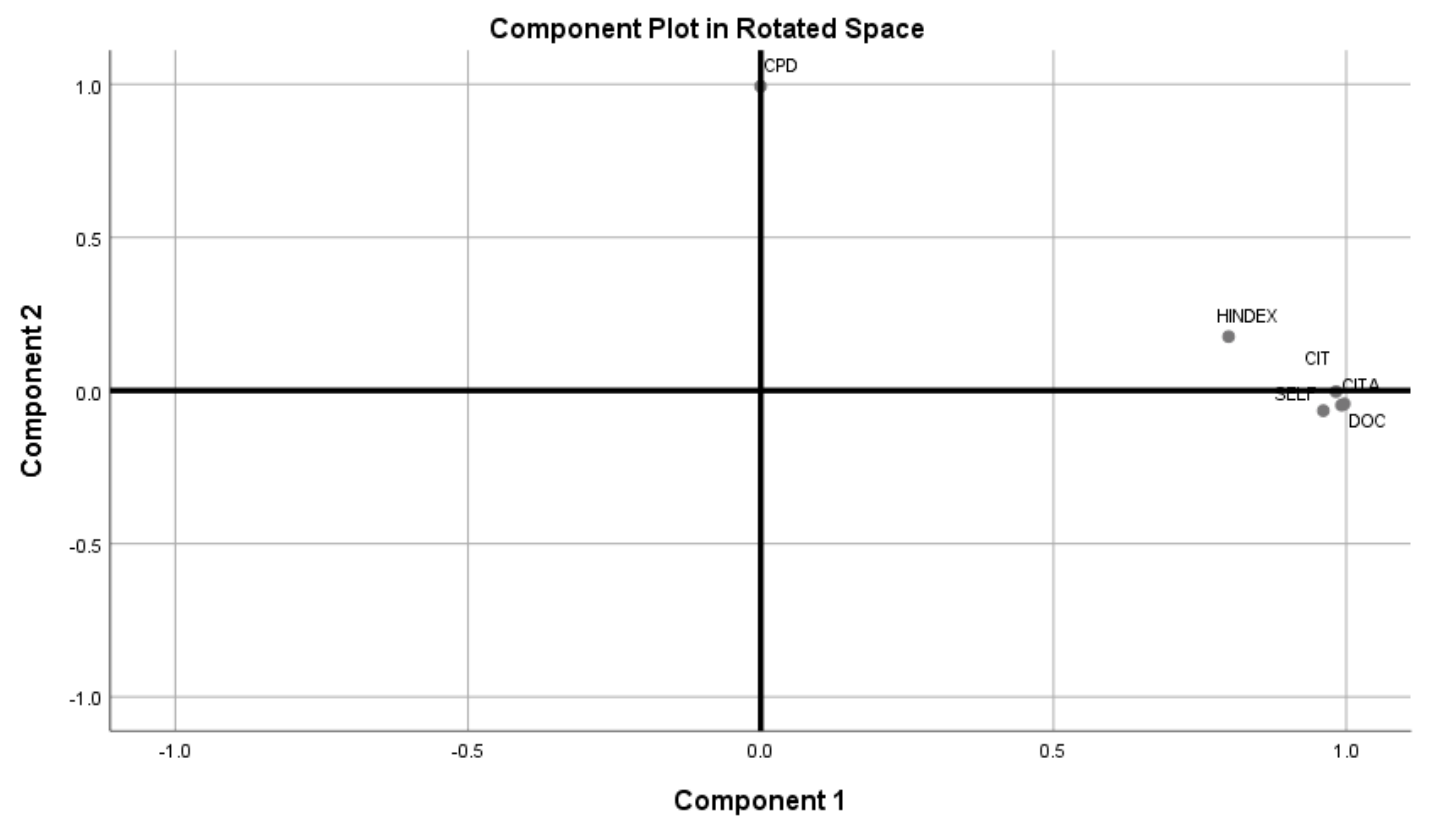

Figure 1. Component plots.

\section{Research performance across regions}

Based on comparisons between regions (Table 4), over the past 23 years (1996-2019) (1) both Eastern Europe and Middle East have better research performance than Latin America, Pacific Region, and Africa; (2) Asiatic region has better research performance than Pacific Region. However, from the aspect of research impact, Latin America outperforms the Middle East, Asiatic Region, and Eastern Europe. Those findings show that research performance and research impact (Table 5) are not always directly proportional, they can even be inversely correlated (Figure 2, Figure 3).

Eastern Europe's superiority in terms of research performance may be due to the rise of democracy, the emergence of the need for research excellence standards, the promotion of international research collaboration, and cooperation with international bodies (such as the World Bank) that enable these countries to enjoy large research grants (Henderson et al., 2012; Švab, 2004).

Henderson et al. (2012) further stated a fact about research culture in Eastern Europe, as follows:

"Though not a uniform phenomenon across all disciplines or countries, some participants noted that in CEE (Central and Eastern Europe) research tends to be more dependent on political power. This can relate both to the partisan provision of financial resources and to researchers' ambitions to convince political actors."
It appears that political activities are melting pots of the interests of academics, politicians, and research funders, which provide work opportunities that has implication in improving research performance in the region's countries. Those interests are given "energy" by the belief of the people that "Our people are not perfect, but our culture is superior to others." (Kim, 2018, para. 6).

Makri's finding (2018) regarding the progressive research achievement of Egypt confirmed the finding that the Middle East has been able to surpass Latin America, the Pacific Region, and Africa in terms of research performance. Different from Eastern Europe, the performance in Middle East has drivers centripetalized on the publishing business. Although some of the Middle East countries are plagued with protracted conflict (Gul et al., 2015), Habibzadeh (2019) noted that there is a "meeting point" between the career interests of faculty members in universities and the business interests of publishing in the countries. This is exacerbated by the relaxation of the promotion standard of faculty members, so that a surge in publication occurs in Scopus indexed journals-that grow rapidly quantitatively in those countries, but of which many have transformed into predatory ones. Habibzadeh (2019, p. 4) conveyed more about the phenomenon:

"Recently, some indexing systems, like Scopus, have also pursued the same strategy and delisted some of the low-quality journals published in the Middle East and Iran. Although some of the editors and publishers of the delisted journals have 
Table 4. Comparison of research performance and impact between regions.

\begin{tabular}{|c|c|c|c|}
\hline Variable & Test statistic & Visualization of mean rank & Pairwise comparison \\
\hline $\begin{array}{l}\text { Research } \\
\text { Performance } \\
\text { (Component 1) }\end{array}$ & $\begin{array}{l}\chi^{2}(6, N=204)=41.952 \\
p=0.000\end{array}$ & Each node shows the sample average rank of Region. & $\begin{array}{l}\text { There are significant differences (marked with } \\
\text { yellow lines in the visualization) between: } \\
\text { - } \quad \text { Pacific Region \& Middle East }(p=0.000) \\
\text { - } \quad \text { Pacific Region \& Eastern Europe }(p=0.000) \\
\text { - } \quad \text { Latin America \& Middle East }(p=0.038) \\
\text { - } \quad \text { Latin America \& Eastern Europe }(p=0.005) \\
\text { - } \quad \text { Africa \& Middle East }(p=0.036) \\
\text { - } \text { Africa \& Eastern Europe }(p=0.004) \\
\text { - } \quad \text { Pacific Region \& Asiatic Region }(p=0.01)\end{array}$ \\
\hline $\begin{array}{l}\text { Research Impact } \\
\text { (Component 2) }\end{array}$ & $\begin{array}{l}\chi^{2}(6, N=204)=29.363 \\
p=0.000\end{array}$ & Each node shows the sample average rank of Region. & $\begin{array}{l}\text { There are significant differences (marked with } \\
\text { yellow lines in the visualization) between: } \\
\text { - } \quad \text { Middle East \& Latin America }(p=0.020) \\
\text { - } \quad \text { Asiatic Region \& Latin America }(p=0.023) \\
\text { - } \quad \text { Eastern Europe \& Latin America }(p=0.001)\end{array}$ \\
\hline
\end{tabular}

$p$-values have been adjusted by the Bonferroni correction for multiple tests; the significance level is 0.05

Table 5. Descriptive statistics of national cultural orientations, research performance and impact.

\begin{tabular}{|c|c|c|c|c|c|c|c|c|c|}
\hline & PDI & IDV & MAS & UAI & LTOWVS & IVR & LGDP & $\begin{array}{c}\text { Research } \\
\text { Performance }\end{array}$ & $\begin{array}{l}\text { Research } \\
\text { Impact }\end{array}$ \\
\hline Valid & 68 & 68 & 68 & 68 & 90 & 91 & 190 & 239 & 239 \\
\hline Missing & 171 & 171 & 171 & 171 & 149 & 148 & 49 & 0 & 0 \\
\hline Mean & 59.118 & 43.853 & 48.603 & 67.132 & 46.067 & 45.374 & 9.008 & $1.004 \mathrm{e}-17$ & $4.766 e-16$ \\
\hline $\begin{array}{l}\text { Std. Error of } \\
\text { Mean }\end{array}$ & 2.671 & 2.930 & 2.420 & 2.820 & 2.560 & 2.364 & 0.088 & 0.065 & 0.065 \\
\hline $\begin{array}{l}\text { Std. } \\
\text { Deviation }\end{array}$ & 22.023 & 24.164 & 19.956 & 23.257 & 24.287 & 22.555 & 1.208 & 1.000 & 1.000 \\
\hline Variance & 485.031 & 583.918 & 398.243 & 540.893 & 589.838 & 508.748 & 1.460 & 1.000 & 1.000 \\
\hline Shapiro-Wilk & 0.985 & 0.942 & 0.980 & 0.951 & 0.968 & 0.978 & 0.979 & 0.264 & 0.915 \\
\hline $\begin{array}{l}p \text { of Shapiro- } \\
\text { Wilk }\end{array}$ & 0.587 & 0.003 & 0.334 & 0.010 & 0.024 & 0.120 & 0.006 & $<.001$ & $<.001$ \\
\hline Minimum & 11.000 & 6.000 & 5.000 & 8.000 & 0.000 & 0.000 & 6.442 & -0.303 & -1.800 \\
\hline Maximum & 104.000 & 91.000 & 110.000 & 104.000 & 100.000 & 100.000 & 11.614 & 12.810 & 5.201 \\
\hline
\end{tabular}

PDI = Power distance; IDV = Individualism (vs. Collectivism); MAS = Masculinity (vs. Femininity); UAI = Uncertainty avoidance; LTOWVS = Long term (vs. Short term) Normative Orientation; IVR = Indulgence (vs. Restraint); LGDP = Natural logarithm of averaged (1993-2018) GDP per capita; Research Performance $=$ Z-scores of Component 1 from Principal Component Analysis/PCA extraction (based on DOC, CITA, CIT, SELF, HINDEX); Research Impact $=$ Z-scores of Component 2 from PCA extraction (based on CPD); PCA = Principal Component Analysis 


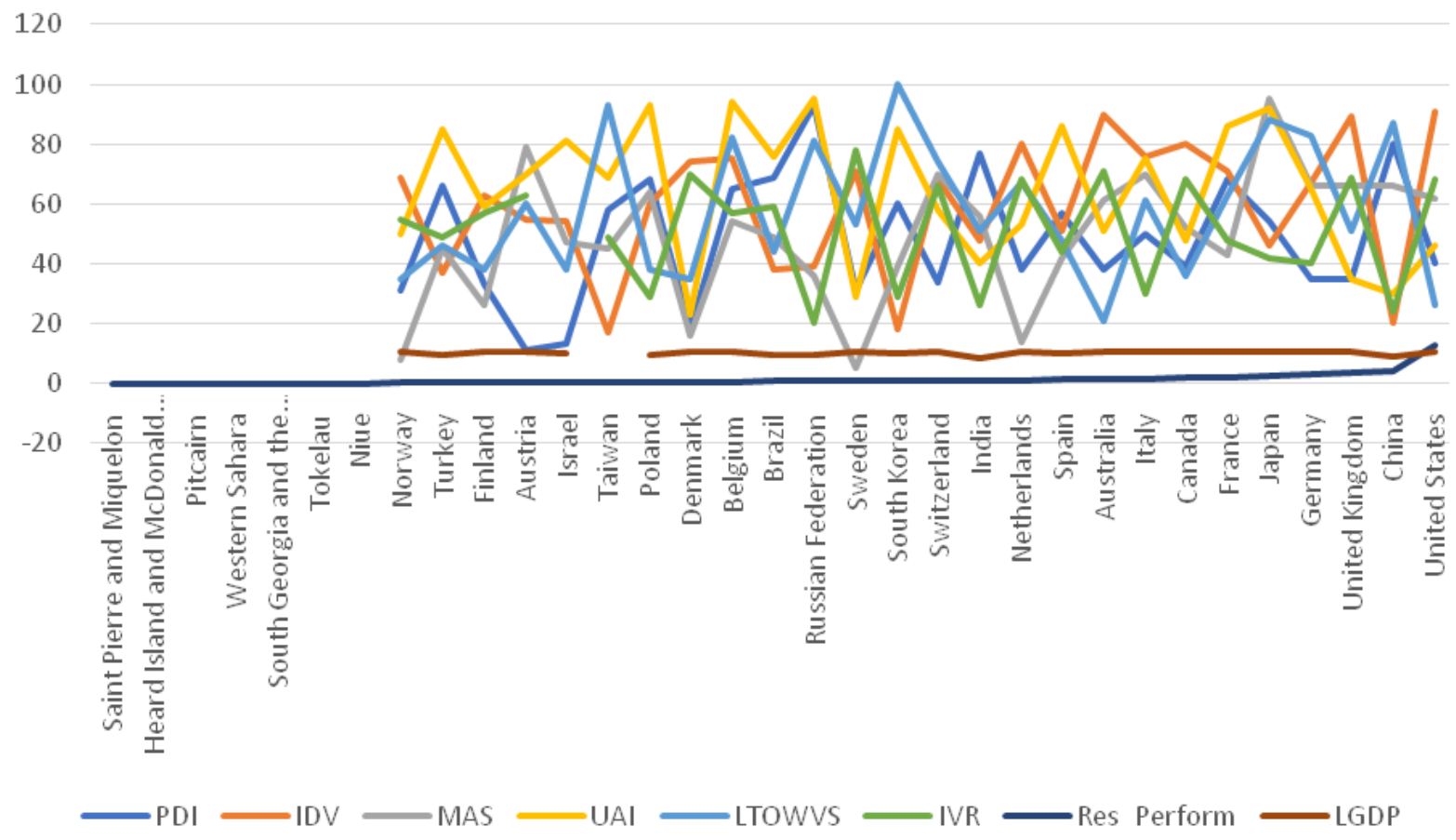

Figure 2. Plots of national cultures, research performance, and Log GDP per capita. PDI = Power distance; IDV = Individualism; MAS = Masculinity; UAI = Uncertainty avoidance; LTOWVS = Long term orientation; IVR = Indulgence; Res_Perform = Research Performance; LGDP = Log GDP per capita.

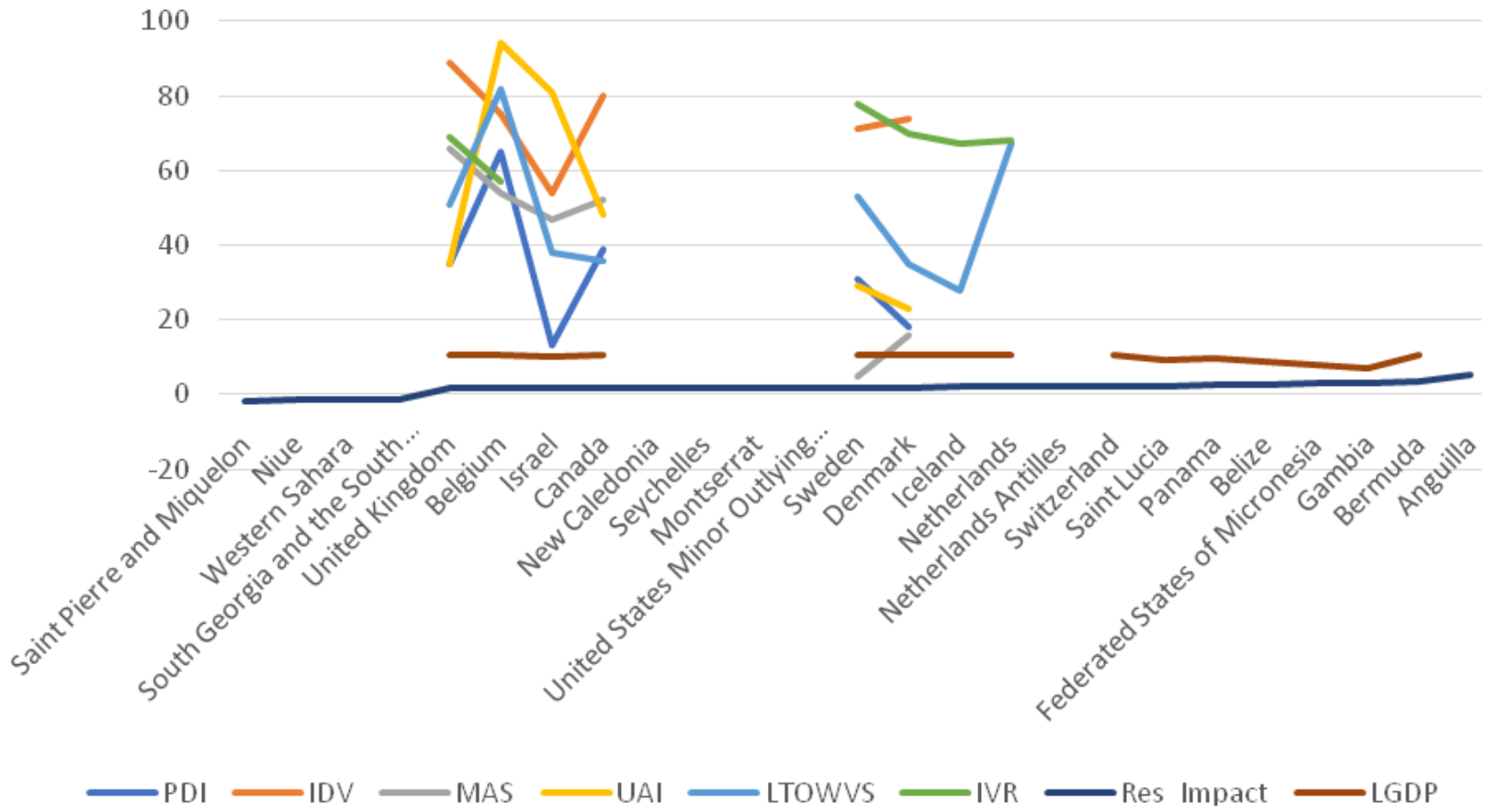

Figure 3. Plots of national cultures, research impact, and Log GDP per capita. PDI = Power distance; IDV = Individualism; MAS = Masculinity; UAI = Uncertainty avoidance; LTOWVS = Long term orientation; IVR = Indulgence; Res_Perform = Research Performance; LGDP = Log GDP per capita. 
attributed these events to political issues, to be honest, I, for one, believe that in most instances, they, themselves, should bear the brunt of the situations they have for their poor work quality." (p. 4)

Noteworthy is the fact mentioned by Plackett (2015), that:

"The predatory journal industry exists on a spectrum-at one end, some such journals maintain they are conducting valid peer review. At the other end of the spectrum, predatory journals sometimes blackmail academics who eventually realize they've published in a journal with a negative reputation." (para. 21)

That is, the issue of predatory journals in the Middle East is not an easy problem to evaluate. This argument is reinforced by Jones' (2015) argument, that the flourish of predatory journals is not the real problem. The fundamental problem, according to Jones, is information inequality; in which case, the prosocial role of librarians and publishers to keep potential writers away from illegitimate journals may still be difficult to expect. It is not surprising that, based on the results of this present study, even though research performance of Middle East outperforms Latin America, in terms of research impact, the opposite occurs, i.e. Latin America outperforms the Middle East, also the Asiatic Region, and Eastern Europe.

\section{Research impact across regions}

Latin America's superiority in terms of research impact cannot be separated from the orientation of studies that aspires to decolonize the research itself (International Institute of Social Studies, 2019), even beginning from the decolonization of consciousness (Garza, 2010). Decolonization of research in the context of Latin America has the meaning of restoring the authentic identity of society, from an oppressed condition-by "capitalism, hegemony, racism, classism, sexism, etc." (Garza, p. 110) - to an emancipated situation. There is hope for reconnection of the daily lives of people and their families, communities, and even living creatures, from those that have been being alienated by the oppression. The assumption is, "You actually cannot have meaningful, impactful research unless you engage communities" (Janes, 2017, p. 114). Studies conducted in Latin America are very directed towards liberating the fate of the society, especially from marginalized conditions in various fields of life, such as in health, agricultural, environmental, social, and other domains.

Meanwhile, the issues of (de-)colonization are studied very seriously by countries that experience a similar fate and become huge energy for doing high impact research. This is because many problems "have been attributed to the impact of ongoing colonization" (Waldram, as cited in Marsh et al., 2015, p. 2). The activities of the academic community of Latin America are increasingly supported by the AmeliCA project, namely The Latin American Initiative which focuses on developing scientific communication systems that are noncommercial, academic-led, and cooperative (Aguado-López \& Becerril-Garcia, 2019), so that could improve citations per document of scientific works in Latin America.
According to SCIMAGOJR data (https://www.scimagojr.com/ countryrank.php?region $=$ Latin $\% 20$ America\&order $=$ cd\&ord $=$ desc), retrieved on September 2019, the six countries with the highest combination of documents and citations are Panama, Puerto Rico, Uruguay, Costa Rica, Argentina, and Chile. Related to the literature in these countries, Ward (2016) stated its virtue, "Only with slow, careful, detailed analysis, concern, and empathy even can be liberated from the old ways of seeing" (p. xxiii). These qualities may attract citations repeatedly. This explanation, nevertheless, is still speculative and requires testing in subsequent empirical studies.

\section{National culture and research performance and impact}

Power distance (PDI) has a negative correlation with research impact (Table 6); this could be because PDI negatively correlates with democracy (Maleki \& Hendriks, 2014). The lower level of democracy reduces the opportunity of the academic community to exchange and market (in the broad sense) scientific information, as well as debate openly. Likewise, democracy that does not flourish deters the use of research results in creating public policies. Science is co-opted or used as just a tool to achieve exclusive interests by ideologues, pundits, and political leaders; they ignore the state-of-the-art nature of the research (Branscomb \& Rosenberg, 2012). In addition, PDI might manifest itself in academic writing in the form of rigid, authoritative, defensive, and dogmatic styles (Koutsantoni, 2005). All the conditions could reduce research impact.

The positive correlations between individualism (IDV) and research performance and impact could be explained using the findings of Deschacht \& Maes (2017). They found that in countries with more individualistic cultures: (1) the scientists prioritize their self-development, (2) the records of scientific work are historically longer (usually Western countries), and (2) self-citations flourish more. This does not necessarily mean that there have been citation abuses, but that self-citation is used to refer to their prior works, thereby, preventing unnecessary repetitions of ideas in newer works (Deschacht, 2017). Although IDV and collaboration are often contested (e.g. Kemp, 2013), a "collaborative individualism" (Limerick \& Cunnington, 1993) - stressing both working together and self-emancipation - is possible, explaining the positive correlation.

Indulgence (IVR) is positively correlated with research impact; this may be because IVR - the warranted one - facilitates academic freedom (Ohmann, 2011), as stated by Jefferson (2011) regarding psychological gratification, "Difference of opinion is advantageous ... [F]ree inquiry must be indulged, and how can we wish others to indulge it while we refuse it ourselves" (p. 26). Conversely, a restraint (as opposed to indulgence) will facilitate the destruction of goal pursuit, e.g. designing and executing impactful studies, through psychological reactance and unwarranted indulgence (Buzinski \& Price, 2015).

Sabbatical leave is a representative example of warranted IVR that faculty members could increase research impact through 


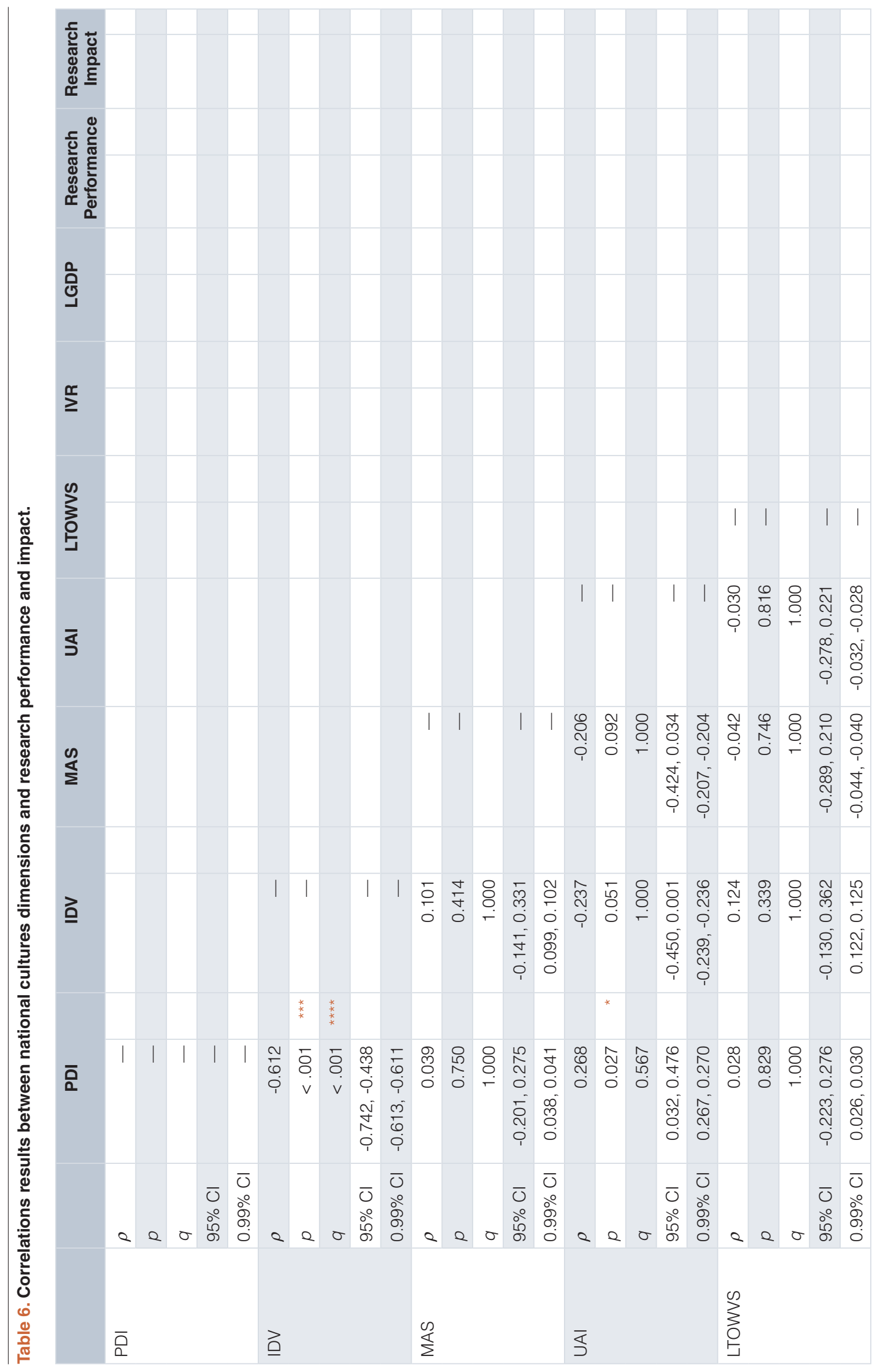




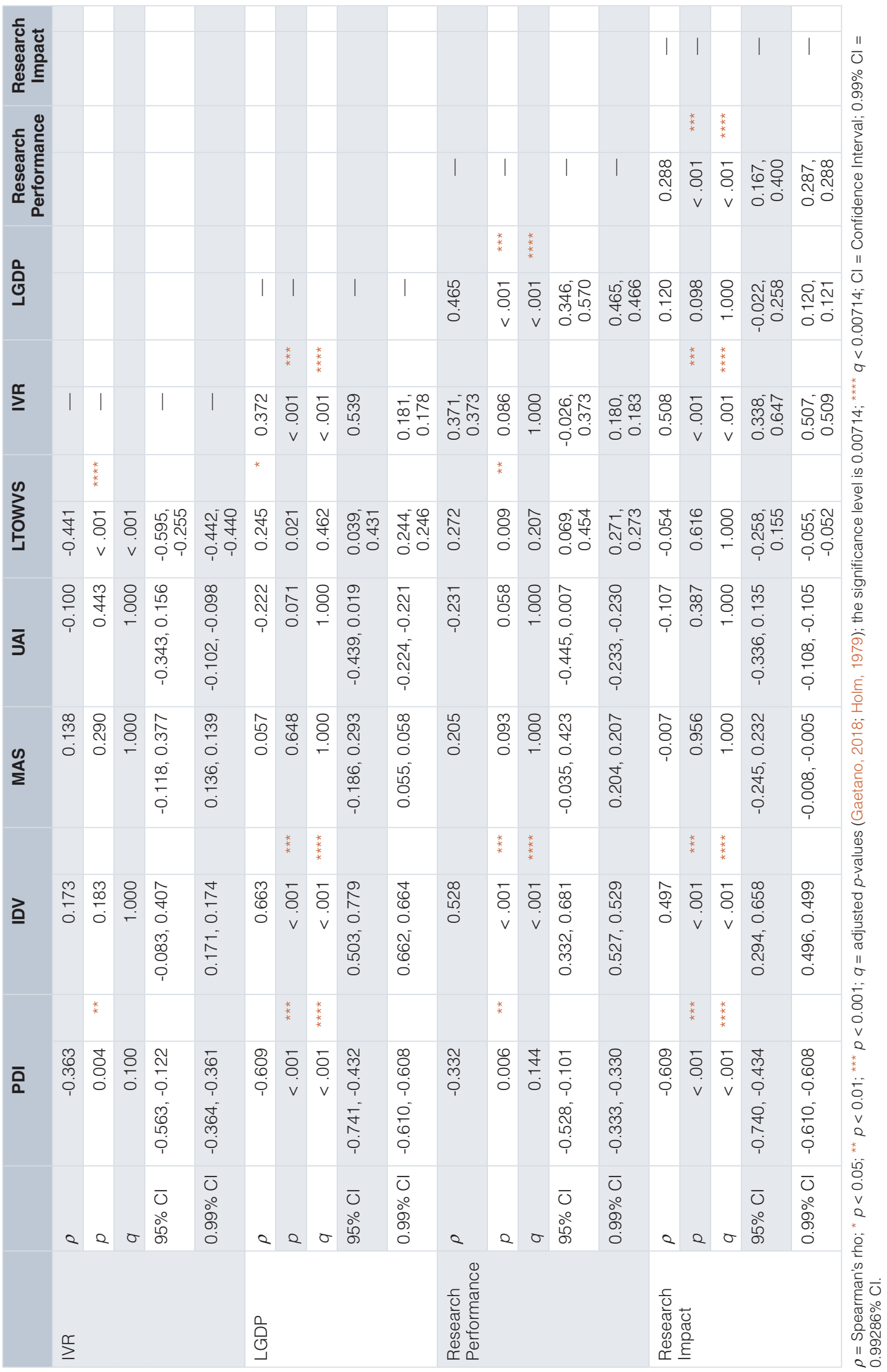


the special time (Robert Gordon University, 2016). Through the leave, faculty members are temporarily freed from normal academic routines and intensively entering the real world where social decisions and policy makings occur. The various experiences expressed in Harvey Mudd College (2019) showed that in undergoing sabbatical leave, faculty members really enjoyed their social, recreational, and cultural adventures, supporting their research life. All the conditions could increase the research quality and, eventually, research impact.

In addition, IVR facilitates open science, because, in the perspective of open science, science is indeed an art (Fleming, 2019; Kera, 2017; Thornton, as cited in BBC News, 2010). Meanwhile, open science practices (such as research sharing through social media and even cartoons and drawings, data archiving and aggregation, team-science, crowd and shared databases, replicability and repeatability improvement efforts, very big data curation and management, engagement with research stakeholders) could enhance research impact in terms of citations per document (CPD) (e.g. De Filippo \& Sanz-Casado, 2018) even in terms of the economy of research (Adams, 2015). This is because open science increases public esteem in science.

IVR may also manifest itself in a "lovely" academic writing style (Kiriakos \& Tienari, 2018). This style is not dry and cold, but rather dialogical, humanistic, more reflexive, and capable of showing authors' courage and vulnerability. Compelling insights are more easily born from the writings that embody those qualities; as mentioned, "a thin line exists between interesting insights and self-indulgence" (Nadin \& Cassell, 2006, p. 214). Scientific authors who read such works would be attracted to cite them, leading to an increase in the works' impact. In addition, "strategic indulgence" is possible and known to be a creative process that enables one to balance academic activity (such as writing) with non-academic ones (Jia et al., 2018) - fostering insight.

Uncertainty avoidance (UAI) is found negatively correlated with research impact (Table 7). This is understandable considering that impactful research requires innovation. The characteristics of UAI - which are intolerant of ideas and practices that are ambiguous and not conventional - do not support innovation
(Bauer \& Suerdem, 2016). Uncertainty avoidance cultural orientation is difficult to challenge and scrape unfunctional attitudes and values that are already stable. Therefore, it will also be hard to produce breakthroughs in research and publication, reducing the potential for citations per document.

One premise advocated by Leiden Manifesto for Research Metrics is "Science and technology indicators are prone to conceptual ambiguity and uncertainty and require strong assumptions that are not universally accepted" (Hicks et al., 2015, para. 21). Higher UAI national culture would adhere to the invariance assumption that is detrimental to the development of science and publication real impact. Un-openness to the pluralistic approach in the impact measurement will invite citation cartels. Citations per document (CPD) will be seen reductionistically as the destination of scientific works, so that CPD will be easy to become a target of manipulation. In fact, we have been reminded that the production of knowledge and its memories must not forget the relevance of knowledge to diverse publics. What is needed is a "careful and conscientious citation ... [citation as] a form of engagement", in which "citation as a crude measure of impact" is only the byproduct of the reflexive action (Mott \& Cockayne, 2017, p. 2, 11). It will need lower UAI.

\section{Conclusion}

National culture dimensions, especially power distance, individualism, indulgence, and uncertainty avoidance are pivotal variables that are to be considered in justifying research impact. In addition, the only variable that correlates with research performance is individualism.

Owing to the fact that the national culture is relatively enduring, countries need to measure their elasticity of hopes and action plans in an effort to boost research performance and impact, by integrating the national culture in the estimate. National culture can be integrated as a moderating variable in the predictive relationship between GDP per capita and research performance and impact. Diversification of this study - based on the document and authors' collaboration types, the indexing databases, the disciplines, as well as the history and development of the research in a country - is a future opportunity for further study.

Table 7. Partial correlations between national cultures dimensions and research performance and impact, controlling Log GDP per capita (LGDP) $(N=60, d f=57)$.

\begin{tabular}{|c|c|c|c|c|c|c|c|}
\hline & & PDI & IDV & MAS & UAI & LTOWVS & IVR \\
\hline \multirow[t]{2}{*}{ Research Performance } & $r$ & -0.061 & 0.303 & 0.201 & -0.176 & 0.011 & 0.026 \\
\hline & $p$ & 0.648 & $0.019^{*}$ & 0.127 & 0.183 & 0.932 & 0.847 \\
\hline \multirow[t]{2}{*}{ Research Impact } & $r$ & -0.495 & 0.432 & -0.086 & -0.261 & -0.112 & 0.273 \\
\hline & $p$ & $0.000^{* * *}$ & $0.001^{* *}$ & 0.518 & $0.046^{*}$ & 0.397 & $0.037^{*}$ \\
\hline
\end{tabular}


Data availability

Source data

Geert Hofstede: Dimension data matrix. https://geerthofstede. com/research-and-vsm/dimension-data-matrix/ (Hofstede et al., 2010)

Scimago Journal \& Country Rank: Download data. https:// www.scimagojr.com/countryrank.php?out=xls (Scimago Lab, 2019)

GDP per capita, PPP (Current International \$). http://api.worldbank.org/v2/en/indicator/NY.GDP.PCAP.PP.CD?downloadformat =excel (World Bank Open Data, 2018)

All source data was accessed and retrieved on the 18/8/2019
Underlying data

Figshare: National culture, research performance indicators, and log GDP Per capita. https://doi.org/10.6084/m9.figshare.7723211 (Abraham, 2019)

Data are available under the terms of the Creative Commons Zero "No rights reserved" data waiver (CC0 1.0 Public domain dedication).

\section{Acknowledgment}

I would like to thank Sandersan (Sandy) Onie for giving advice on statistical data processing in addressing a number of criticisms from the peer reviewers of this manuscript.
Abraham J: National culture, research performance indicators, and log GDP per capita. [Data set]. Figshare. 2019.

http://www.doi.org/10.6084/m9.figshare.7723211

Adams J: Impact of open science methods and practices on the economics of research and science: Case studies from life, mathematical and social sciences. Directorate-General for Research and Innovation, European Commission. 2015.

Reference Source

Aguado-López E, Becerril-Garcia A: AmeliCA before Plan S - The Latin American Initiative to develop a cooperative, non-commercial, academic led, system of scholarly communication. 2019.

Reference Source

Bauer MW, Suerdem A: Relating 'science culture' and innovation. OECD Blue Sky meeting on Science and Innovation Indicators. 2016.

Reference Source

BBC News: The art of science. 2010.

Reference Source

Blanco LR, Gu J, Prieger, JE: The impact of research and development on economic growth and productivity in the U.S. States. South Econ J. 2015; 82(3): 914-934.

Publisher Full Text

Branscomb LM, Rosenberg AA: Science and democracy. 2012. Reference Source

Buzinski SG, Price A: Don't tell me what to do: highly restrictive goals promote temptation indulgence. Sage Open. 2015; 5(3): 1-11.

Publisher Full Text

Claudia GB, Francisco MV: The determinants of research output and impact: A study of Mexican researchers. Res Policy. 2007; 36(7): 1035-1051.

Publisher Full Text

De Filippo D, Sanz-Casado E: Bibliometric and Altmetric analysis of three social science disciplines. Front Res Metr Anal. 2018; 3.

Publisher Full Text

Demaria A: Research productivity among nations. J Am Coll Cardiol. 2009; 54(25): 2460-2462.

PubMed Abstract | Publisher Full Text

Deschacht N, Maes B: Cross-cultural differences in self-promotion: A study of self-citations in management journals. J Occup Organ Psychol. 2017; 90(1): 77-94.

Publisher Full Text

Deschacht N: Me, myself, and I: self-citation rates are higher in individualist cultures than in collectivist cultures. 2017.

Reference Source

Fleming J: How the way scientists share data is changing. 2019. Reference Source

Gaetano J: Holm-Bonferroni sequential correction: An Excel calculator (1.3) [Microsoft Excel workbook]. 2018.

Publisher Full Text

Garza V: Decolonization of the mind and spirit: Healing strategies through

Latin@ critical consciousness. Doctoral Dissertations. 2010.

Reference Source

Guerrero-Bote VP, Moya-Anegón F: A further step forward in measuring journals' scientific prestige: The SJR2 indicator. J Informetr. 2012; 6(4): 674-688.

Publisher Full Text

Gul S, Nisa NT, Shah TA, et al.: Middle East: Research productivity and performance across nations. Scientometrics. 2015; 105(2): 1157-1166. Publisher Full Text

Habibzadeh F: Open access journals in the Middle East and Iran. $J$ Korean Med Sci. 2019; 34(16): e123.

PubMed Abstract | Publisher Full Text | Free Full Text

Harvey Mudd College: Faculty and staff activities 2015. 2019.

Reference Source

Harzing A: Two new kids on the block: How do Crossref and Dimensions compare with Google Scholar, Microsoft Academic, Scopus and the Web of Science? Scientometrics. 2019; 120(1): 341-349.

Publisher Full Text

Henderson K, Pettai V, Wenninger A: Central and Eastern Europe beyond transition: Convergence and divergence in Europe. European Science Foundation (ESF). 2012

Reference Source

Hicks D, Wouters P, Waltman L, et al.: Bibliometrics: The Leiden Manifesto for research metrics. 2015.

Reference Source

Hofstede G, Hofstede GJ, Minkov M: Cultures and Organizations: Software of

The Mind. McGraw Hill, New York, 2010.

Reference Source

Hofstede Insights: National culture. 2019.

Reference Source

Holm S: A Simple Sequentially Rejective Multiple Test Procedure. Scand J Stat. 1979; 6(2): 65-70.

Reference Source

International Institute of Social Studies: Research on decolonization or decolonizing research? Perspectives from the margins. 2019

Reference Source

Janes JE: Governance through participation: An inquiry into the socia relations of community-based research. Doctoral Dissertations. 2017.

Reference Source

Jefferson T: The Writings of Thomas Jefferson: Being His Autobiography, Correspondence, Reports, Messages, Addresses, and Other Writings, Official and Private. Cambridge University Press, Cambridge, UK, 2011.

Reference Source

Jia L, Hirt ER, Koh AH: How to have your cake and eat it too: strategic indulgence in big-time collegiate sports among academically successful students. Soc Psychol Personal Sci. 2018; 10(6): 792-801.

Publisher Full Text

Jones P: Predatory publishing isn't the problem, it's a symptom of information inequality. 2015.

Reference Source

Kemp AT: Collaboration vs. individualism: what is better for the rising academic? Qual Rep. 2013; 18(50): 1-8.

Reference Source

Kera D: Science artisans and open science hardware. Bull Sci Technol Soc. 
2017; 37(2): 97-111.

Publisher Full Text

Kim A: Eastern Europeans more inclined to see their culture as superior [survey]. 2018

Reference Source

Kiriakos CM, Tienari J: Academic writing as love. Manag Learn. 2018; 49(3): 263-277.

Publisher Full Text

Koutsantoni D: Greek cultural characteristics and academic writing. J Mod Greek Stud. 2005; 23(1): 97-138.

Publisher Full Text

Limerick D, Cunnington B: Collaborative Individualism and The End of The Corporate Citizen. In: Limerick D, Cunnington B (eds). Managing The New Organisation. Chapter 4. Business and Professional Publishing, Chatswood, 1993. Reference Source

Makri A: Pakistan and Egypt had highest rises in research output in 2018. Nature. 2018.

Publisher Full Text

Maleki A, Hendriks F: The relation between cultural values and models of democracy: a cross-national study. Democratization. 2014; 22(6): 981-1010. Publisher Full Text

Marsh TN, Cote-Meek S, Toulouse $\mathrm{P}$, et al:: The application of two-eyed seeing decolonizing methodology in qualitative and quantitative research for the treatment of intergenerational trauma and substance use disorders. Int $J$ Qual Methods. 2015; 14(5): 1-13.

Publisher Full Text

Maseland R, van Hoorn A: Culture at the country level. In: van Herk H, Torelli CJ (eds.). Cross Cultural Issues in Consumer Science and Consumer Psychology. Springer, New York, 2017; 7-32.

Publisher Full Text

Mott C, Cockayne D: Citation matters: Mobilizing the politics of citation toward practice of "conscientious engagement". Gend Place Cult. 2017; 24(7): 953-973. Publisher Full Text

Mueller $\mathrm{CE}$, Gaus $\mathrm{H}$, Konradt I: Predicting research productivity in internationa evaluation journals across countries. J Multidiscip Eval. 2016; 12(27): 79-92. Reference Source
Nadin S, Cassell C: The use of a research diary as a tool for reflexive practice: Some reflections from management research. Qualitative Research in Accounting \& Management. 2006; 3(3): 208-217.

Publisher Full Text

Ohmann R: Academic freedom's best days. Inside Higher Ed. 2011.

Reference Source

Plackett B: Predatory journals lure in Arab researchers. Al-Fanar Media. 2015. Reference Source

Robert Gordon University: Sabbatical leave scheme and procedures. 2016. Reference Sourc

Scimago Lab: Scimago journal \& country rank. [Data set]. 2019

https://www.scimagojr.com/countryrank.php

Sen A: How Does Culture Matter? In: Rao V, Walton M (eds). Culture and Public Action. Chapter 2. Stanford University Press, Stanford, California, 2004.

Reference Source

Signorini P, Wiesemes R, Murphy R: Developing alternative frameworks for exploring intercultural learning: a critique of Hofstede's cultural difference model. Teach High Educ. 2009; 14(3): 253-264.

Publisher Full Text

Suryani I, Yaacob A, Hashima N, et al:: Research publication output by academicians in public and private universities in Malaysia. Int $J$ High Educ. 2013; 2(1): 84-90

Publisher Full Text

Švab I: Changing research culture. Ann Fam Med. 2004; 2 Suppl 2: s30-s34. PubMed Abstract | Publisher Full Text | Free Full Text

van Eck NJ, Waltman L, Larivière $V$, et al.: Crossref as a new source of citation data: A comparison with Web of Science and Scopus. 2018.

Reference Source

Ward T: Decolonizing Indigeneity: New Approaches to Latin American Literature. Lexington Books, 2016.

Reference Source

World Bank Open Data: GDP per capita, PPP (current international \$). 2018. Reference Sourc

Xiaomei B, Hui L, Fuli Z, et al.: An overview on evaluating and predicting scholarly article impact. Information. 2017; 8(3): 73.

Publisher Full Text 


\section{Open Peer Review}

\section{Current Peer Review Status: ? ?}

\section{Version 2}

Reviewer Report 25 November 2019

https://doi.org/10.5256/f1000research.22695.r54254

(C) 2019 Tennant J. This is an open access peer review report distributed under the terms of the Creative Commons Attribution License, which permits unrestricted use, distribution, and reproduction in any medium, provided the original work is properly cited.

\section{Jonathan P. Tennant \\ IGDORE, Berlin, Germany}

From what I can see, the author has made a number of important changes to this MS, which feels much stronger in its present version. This includes:

Almost completely rewriting the abstract

Far more additional information on the source data and methods have been added

Tables summarising the results have been added now, largely in place of text blocks describing the statistical results

Additional principal component analyses have been performed

The discussion has been almost entirely rewritten based on this, including a section on limitations of the data and analyses

I note here that Reviewer 2 has also provided some additional comments in their second review. I agree with both of these points, that the labelling of the PCA plots should be checked and made more appropriate, and that the results section would still benefit from a combined text and table presentation. I think this would entail just re-adding some of the deleted text from the previous version. I think that keep the results and discussion sections distinct though would be beneficial, as there is a lot to digest here. The present version is a bit weird with all of the results condensed into one table, referring to further results which are only then first present in the discussion.

\section{Additional comments}

Looking at the data again, I am still a bit worried that this involves time series data, but they are not being treated as such. Thus, the results are most likely suffering from autocorrelation or long-term impacts of background trends, and require further statistical analysis to be sure of this. I am really only familiar with time series analysis for palaeontological data though, see for example here:

https://www.nature.com/articles/ncomms12737\#Sec11 1 - I am a bit suspicious that because of this problem, many of the correlation coefficients reported might be artificially higher than what is realistic. I think that this needs to be very carefully considered here. My apologies for not indicating this in the first report, but I could not see the data to check this. The limitations section might work better after the rest of the discussion 
My expertise on the intersection between politics and research is quite limited, and I will refrain from commenting on those elements of the discussion. Although they are, at least to me, very interesting!

As much of the discussion again is based on the results, which I suspect might change given my recommendations for the methods above, I will refrain from commenting on them too much at the present. From what I can gauge though, they seem to be well thought out, contain relevant literature, and do not oversell the results too much (in their present state). My apologies for asking for potentially more analytical work to be done at this stage. I feel that it is necessary to look at the data through the lens of time though to better understand some of the results being obtained here. Keep up the great work for now!

\section{References}

1. Tennant J, Mannion P, Upchurch P: Sea level regulated tetrapod diversity dynamics through the Jurassic/Cretaceous interval. Nature Communications. 2016; 7 (1). Publisher Full Text

Competing Interests: No competing interests were disclosed.

Reviewer Expertise: Palaeontology, Open Scholarly Communication

I confirm that I have read this submission and believe that I have an appropriate level of expertise to confirm that it is of an acceptable scientific standard, however I have significant reservations, as outlined above.

Reviewer Report 14 October 2019

https://doi.org/10.5256/f1000research.22695.r54253

(C) 2019 Waltman L. This is an open access peer review report distributed under the terms of the Creative Commons Attribution License, which permits unrestricted use, distribution, and reproduction in any medium, provided the original work is properly cited.

\section{Ludo Waltman (it)}

Centre for Science and Technology Studies (CWTS), Leiden University, Leiden, The Netherlands

The author has made various improvements. However, the revised paper suffers from two problems that I would like to request the author to address. The first problem is a major one, while the second one is more minor.

First, the results section consists of just one sentence and doesn't properly present and explain the results. Instead, a summary of the results is presented in Table 1 and this table then provides references to other tables and figures. Based on Table 1, I find it difficult to get a good understanding of the results. Without such an understanding, I also struggle to understand the discussion section. My recommendation is to remove Table 1 and to provide a proper presentation of the results in the results section. Since I didn't manage to properly understand the results, I refrain from commenting on the discussion of the results in the discussion section. The author could also consider combining the presentation and the discussion of the results in a single section called 'Results and Discussion'. 
Second, in the principal component analysis, I don't think the first component should be labeled 'research performance'. The term 'research performance' is very general and could mean many different things. Therefore, 'research performance' is not a very helpful label for the first component. The essential difference between the two components is that the first one consists of size-dependent variables (i.e., variables that increase with the number of publications of a country) while the second component consists of a size-independent variable (i.e., a variable that is independent of the number of publications of a country). The first component could be labeled 'research output' (since all variables depend on the size of the research output of a country), while the second one could be labeled 'research impact'.

Competing Interests: No competing interests were disclosed.

Reviewer Expertise: I am an expert in scientometrics. I don't have any specific expertise on the cultural orientation of countries.

I confirm that I have read this submission and believe that I have an appropriate level of expertise to confirm that it is of an acceptable scientific standard, however I have significant reservations, as outlined above.

\section{Version 1}

Reviewer Report 15 April 2019

https://doi.org/10.5256/f1000research.20000.r46347

(c) 2019 Waltman L. This is an open access peer review report distributed under the terms of the Creative Commons Attribution License, which permits unrestricted use, distribution, and reproduction in any medium, provided the original work is properly cited.

\section{Ludo Waltman}

${ }^{1}$ Centre for Science and Technology Studies (CWTS), Leiden University, Leiden, The Netherlands

${ }^{2}$ Centre for Science and Technology Studies (CWTS), Leiden University, Leiden, The Netherlands

This is a short paper that presents a brief but easy-to-understand analysis of the correlation between the cultural orientation of countries and countries' scientific performance in terms of bibliometric statistics.

It would be helpful if the author could offer more extensive information on the way in which the variables used in the analysis have been obtained. The definitions of the bibliometric variables need to be carefully explained. Likewise, it should be explained how the variables for national cultural orientations have been obtained.

The statistical analysis is carried out using Pearson correlation analysis. Before presenting the correlations, the author should present descriptive statistics for the variables included in the 
analysis. In particular, I would like to know whether some of the variables may be highly skewed. If this is the case, the use of Pearson correlation analysis could easily lead to misleading results. The use of for instance the Spearman correlation may then be more appropriate.

The author relies strongly on statistical significance testing. My recommendation is to leave out all significance tests and instead to present confidence intervals for the correlation coefficients. Significance testing leads to problematic dichotomous thinking, as has for instance been pointed out in a recent contribution in Nature (Amrhein et al. ${ }^{1}$ ). Following the so-called estimation statistics approach, reporting confidence intervals is preferable over reporting significance tests ( https://en.wikipedia.org/wiki/Estimation_statistics). I am aware that another reviewer (Tennant) recommends performing even more significance tests. I disagree with this recommendation. I don't consider this to be good statistical practice.

It would be nice if the author could deepen the analysis a bit more. This can for instance be done by showing scatter plots for the most interesting relationships between variables. In these scatter plots, the names of countries could be shown, especially for those countries that seem to display interesting behavior (e.g., outliers). This would lead to a more in-depth analysis that probably offers richer insights.

The paper uses lots of abbreviations. This makes the paper more difficult to read. My recommendation is to reduce the number of abbreviations that are used. It may also be helpful to include a table listing all abbreviations and the corresponding full terms.

The author interprets the analysis in terms of correlation instead of causation. This is very good. There is a risk, however, that some readers may give causal interpretations to the findings of the author. My suggestion is to add a sentence at the end of the paper emphasizing that causal interpretations are not warranted.

\section{References}

1. Amrhein V, Greenland S, McShane B: Scientists rise up against statistical significance. Nature. 2019; 567 (7748): 305-307 Publisher Full Text

Is the work clearly and accurately presented and does it cite the current literature? Yes

Is the study design appropriate and is the work technically sound? Partly

Are sufficient details of methods and analysis provided to allow replication by others? Yes

If applicable, is the statistical analysis and its interpretation appropriate? Partly

Are all the source data underlying the results available to ensure full reproducibility? Yes

Are the conclusions drawn adequately supported by the results? 
Yes

Competing Interests: No competing interests were disclosed.

Reviewer Expertise: I am an expert in scientometrics. I don't have any specific expertise on the cultural orientation of countries.

I confirm that I have read this submission and believe that I have an appropriate level of expertise to confirm that it is of an acceptable scientific standard, however I have significant reservations, as outlined above.

Reviewer Report 28 March 2019

https://doi.org/10.5256/f1000research.20000.r46349

(c) 2019 Tennant J. This is an open access peer review report distributed under the terms of the Creative Commons Attribution License, which permits unrestricted use, distribution, and reproduction in any medium, provided the original work is properly cited.

Jonathan P. Tennant

${ }^{1}$ IGDORE, Berlin, Germany

2 IGDORE, Berlin, Germany

The author presents an interesting piece of insight into research impact through a cultural lens, which is quite distinct from a lot of more recent studies which tend to focus on 'academic impact' metrics. As a short note, I found it useful in exposing a different dimension to the ongoing debates around research impact. Given my area of "expertise", I feel that someone who understands social research impact more could provide a great deal of additional insight here during the review process.

\section{Data}

The data are included in Figshare, as well as summarized in integrated tables.

I note that there are a lot of missing data included though, is this just a case of availability?

Also, I note that the Scimago database is based on Scopus data, which tends to be biased in

\section{Abstract} a number of dimensions. Is it possible to make a note of this?

The abstract jumps right into results around Individualism and Power distance and indulgence, without describing what these are (even briefly). This makes it difficult to understand for readers who are perhaps unfamiliar with these concepts. Perhaps a brief explanation of these could be added instead of describing the methods and the data sources, which aren't really needed?

\section{Introduction}

Just to pull out the 'correlation does not imply causation' card here; just because there is a correlation between number of publications and other external factors, does not imply a causal relationship necessarily.

There are a couple of typos (e.g.'twits') that might just need a quick copy edit to fix. 
I think the Introduction does a nice job of describing the previous research, and situates the present report well within that.

Not sure if the comment about China at the end of the Introduction adds too much here.

\section{Materials and methods}

So the methods are pretty simple, which is nice. But also, I think perhaps a bit too simple here given that you're performing a lot of bivariate analyses, and a couple of extra steps are recommended.

First, you want to perform an assessment of normality for data series prior to any correlation analyses, using the Shapiro-Wilk test (e.g., shapiro.test function in R). From the output, if the $p$-values are greater than the pre-defined alpha level (traditionally, 0.05 ) this implies that the distribution of the data are not significantly different from a normal distribution, and therefore you can assume normality and use Pearson's test (Pearson's product moment correlation coefficient $[r])$. If $p>0.05$, you should instead perform a non-parametric Spearman's rank correlation $(\rho)$. Secondly, once you've done this, for each test, report both the raw and adjusted pvalues. The latter can be calculated using the p.adjust() function, and using the ' $\mathrm{BH}$ ' model (Benjamini \& Hochberg, 1995 ${ }^{1}$ ). This method accounts for the false-discovery test when performing multiple hypothesis tests with the same data set, which can inflate type-1 error (i.e. in order to avoid falsely rejecting a true null hypothesis; a false positive). What this will probably do is reduce the 'significance' of some of your results too (which is why it's best to report both the raw and adjusted values).

In addition to this, it seems like you have multivariate data, so multivariate analyses might be more informative here. I would strongly recommend performing a Principal Components Analysis on your data (perhaps just only with the variables with more complete data), and inspecting that as a compliment to the bivariate ones. This is fairly easy to do and display

\section{Results} using in built functions in $\mathrm{R}$.

- I expect that the results will change a bit given my above recommendations to the methods, so won't comment too much on them at this stage. The nice thing about PCA though is that it produces good summary plots, which might be useful here.

In the text, can the country abbreviations be given to make reading a bit easier?

$\mathrm{M}, \mathrm{SD}$, and $\mathrm{N}$ I think need explaining here too. Lots of acronyms can get a bit confusing!

\section{Discussion and conclusions}

As above, I don't want to comment too much on the Discussion and Conclusions at the present, as I think the above recommended methods will change some of the interpretations. However, at the present there seems to be a logical progression between reported results and conclusions.

Congratulations to the author on a great and interesting piece of work. I would be happy to see a revised version of this too if needed.

\section{References}

1. Benjmini Y, Hochberg Y: Controlling the False Discovery Rate: A Practical and Powerful Approach to Multiple Testing. Journal of the Royal Statistical Society. Series B (Methodological). 1995; 57.

Reference Source

\section{Is the work clearly and accurately presented and does it cite the current literature?}


Yes

Is the study design appropriate and is the work technically sound?

Partly

Are sufficient details of methods and analysis provided to allow replication by others? Yes

If applicable, is the statistical analysis and its interpretation appropriate? Partly

Are all the source data underlying the results available to ensure full reproducibility? Yes

Are the conclusions drawn adequately supported by the results?

Yes

Competing Interests: No competing interests were disclosed.

Reviewer Expertise: Palaeontology, Open Scholarly Communication

I confirm that I have read this submission and believe that I have an appropriate level of expertise to confirm that it is of an acceptable scientific standard, however I have significant reservations, as outlined above.

The benefits of publishing with F1000Research:

- Your article is published within days, with no editorial bias

- You can publish traditional articles, null/negative results, case reports, data notes and more

- The peer review process is transparent and collaborative

- Your article is indexed in PubMed after passing peer review

- Dedicated customer support at every stage

For pre-submission enquiries, contact research@f1000.com 